alteration. Of course Fignre 9 is generalized, and the details might be varied; as, for instance, by some of the faults bifurcating or by step faults.

I think it possible that "our science" is more in danger of "losing caste" by the Professor's critique, than by my article. It seems to be the especial misfortune of Geology, that questions relating to it cannot be discussed dispassionately-I had almost written with courtesy. I can only hope that some of your readers have understood my meaning better than Mr. Blake has done.

O. Frsher.

Fig. 8 .

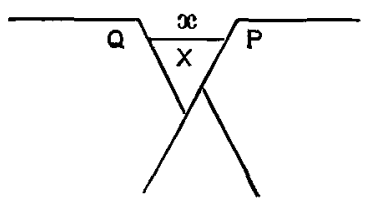

13 Aug. 1884.
Fig. 9.

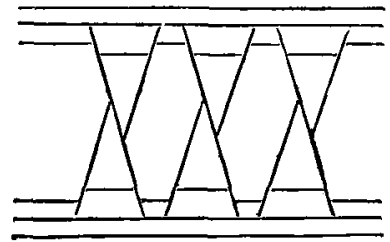

\title{
REPLY TO PROF. BLAKE'S CRITICISM ON FAULTS.
}

Sir,-_Having been much interested in the two suggestive papers by my friend Mr. Fisher on the subject of Faulting, Jointing and Cleavage, lately published in this Magazine, I was naturally somewhat surprised at being told last month, on the anthority of Prof. Blake, that the papers in question were a "mischievous" compound of mere "chaff." I have, therefore, carefully gone over the original papers again (including the equations which the Professor condemns as erroneous), with Prof. Blake's article as a guide; the result being that the whole of the long and somewhat violent criticism shows itself to be a mixture of errors and misapprehensions so extraordinary as to make one wonder what the Professor can have been about in writing such an article for publication. He certainly points out the obvious error in Figs. 8 and 9; but even in doing this he has allowed himself to fall into the mistake of giving an obviously imaginary reason for this error. The figures are easily corrected; and when this is done, it will be seen that there is no need for any correction in the text, nor any alteration in the argument; so far is it from being true, as the critic asserts, that the error in the figures is " the result of attempting to form faults" either in the way suggested by Mr. Fisher, or in the parody thereof suggested by the critic. Again, on p. 212, 1. 26, Mr. Fisher has omitted the letter $x$ after $\lambda$ (unless, indeed, he here uses the symbol $\lambda$ merely to identify the force spoken of, which appears to me the probable explanation). This, which is at worst a mere clerical error, cannot have caused any confusion except perhaps in the critic's mind. But Prof. Blake has seized the opportunity to "run full tilt" at the whole paper in consequence. One other criticism offered by Prof. Blake may appear to some to be of some weight, when he doubts (on p. 368) whether Mr. Fisher is right in assuming that the resis- 
tance to shearing stress along a plane is independent of the pressure perpendicular to that plane. With regard to this, however, it must be remembered that the shearing stress spoken of is not employed to overcome friction, but to induce viscous motion; and it is difficult to see how this can be affected by normal pressure, unless perbaps when the matter is compressible.

But when we turn to the rest of the violent attack, made on papers which treat of a difficult subject in a sufficiently simple way, one is puzzled to know what in the world cun have induced any one who cares for his reputation to commit such egregious blunders to print, even in the form of a criticism. And I hope Prof. Blake will excuse my giving an example or two which will, I think, be sufficient to show him that, in his anxiety to save your fledgeling readers from danger, he had unconsciously done the very opposite. In his remarks on Mr. Fisher's first paragraph, he supposes that we are told to confound "vertical" with "perpendicular to the bedding," whereas in fact Mr. Fisher (after suggesting that by the ordinary artifice of turning a whole area together with the directions of the forces affecting it back through the angle of dip, his formulæ, which are based on horizontally stratified areas, will, with the necessary modifications, apply generally ${ }^{1}$ ) merely warned his readers to make these modifications. He makes an extraordinary error also when he gives those two instances to show that Mr. Fisher was wrong in stating that the idea of plasticity would be introduced by the assumption that pressure varies as the area on which it acts. On what part of a steam-boiler does the pressure vary as the area, except on those surfaces on which the plastic steam or the plastic atmosphere acts? And even Prof. Tait, the terror of whose name Prof. Blake invokes in another part of his critique, would be puzzled to determine what is the pressure per unit area exerted by a rigid book on a rigid table; we used to learn that the pressure so created was indeterminate if exerted at more than 3 points; but as soon as we "introduce the idea of plasticity," it is obvious that the pressure will then vary as the area.

So much for the barren labour of criticizing the criticism. If however, you will allow me a little more space, I should like to add a few words on the original papers. Mr. Fisher starts with the assumption that the lack of horizontal support, which seems necessary to account for direct faulting, is probably in many cases due to contraction on solidification; and then, as it seems to me, follows out logically the consequences of that assumption. Nowhere can the existence of this proposed cause be more easily ascertained than in the "slurries" of the Cambridgeshire coprolite pits; thongh the small vertical pressure exerted by the shallow deposits in these slurries is not, I suspect, sufficient to give rise to faulting. Now no one with any knowledge of mathematics would expect that the equations of motion of plastic solids submitted to forces thus generated, even if they could be obtained, could be integrated; so

1 Your readers will forgive my explaining this at such length. 
that it is hopeless to look in this direction for any workable results. And this being so, it is necessary to attack this problem, as many other problems have had to be attacked, in a more roundabout way. Mr. Fisher finds, if I am not mistaken, the statical conditions of equilibrium in such solids when the forces exerted on them have increased to such an extent that they are on the point of exhibiting their plastic character. In doing so, however, he only considers the forces acting on the solid vertically and in one horizontal direction. It might perhaps lead to a useful result if he extended his method to the consideration of the problem in three dimensions, as it seems probable that another tension $Q$, corresponding to his tension $P$, but in a direction perpendicular to that of $P$, must arise during contraction. His present results agree in many respects with what we find in nature. Thus he leads us to expect that no direct faults caused by contraction will have less inclination to the horizon ${ }^{1}$ than $45^{\circ}$. I do not know of any of less inclination than this, but if any such exist, the fact may most probably be accounted for on the supposition that the whole strata, fault and all, have been subsequently turned through an angle of dip sufficient to change the hade to its present value. He also leads us to expect that series of crossed faults will consist of two more or less parallel systems. A careful examination of series of faults with such a guide to our enquiries as Mr. Fisher's papers will afford, will be of infinitely more value to geology than any amount of random onslaught by careless critics.

A. F. Griffith, M.A.

Sanipridge, St. Albans, August $12 t h, 1884$.

\section{THE PERMANENCE OF OCEAN BASINS.}

Sir,--Mr. Mellard Reade has drawn attention to the discovery that South Georgia is not a volcanic island, but is composed of clay-slate: ${ }^{2}$ and argues from this fact against the theory of the Permanence of Oceanic and Continental Areas. He very fairly remarks that, if islands like New Zealand are largely composed of sedimentary rocks, they are said not to be oceanic, and that in arguing from the position that all truly oceanic islands are volcanic, the advocates of the theory arbitrarily exclude the non-volcanic from the category of oceanic islands.

There is, however, something to be said on the other side. The non-volcanic islands mentioned by Darwin in his "Coral Islands" are New Caledonia, and the Comoro and Seychelles. New Caledonia seems to be a link in the chain which connects New Zealand with New Guinea, and lies in the course of the great volcanic band which stretches through Java to New Zealand. The Comoro islands are too near Africa to be called oceanic; and the Seychelles appear to be on the axis of Madagascar, and may well be connected with it.

1 There seems to be much uncertainty among geologists as to the use of the word "hade." Among miners it appears to be measured always from the vertical, and it would perhaps be well for us to assimilate our use of the word to theirs, as we borrowed the term from them.

2 Geol. Mag. May, 1884. 